\title{
SUBJECT OF MATERIALS VERIFICATION OF THE CRIMINAL CASE IN THE COURT
}

\author{
Tatyana K. Ryabinina \\ Southwest State University, Kursk, Russian Federation
}

\begin{abstract}
Introduction. The article deals with the problem of determining the verification of the materials of the criminal case, submitted to court for trial. The complexity of the identified problems stems from the fact that the criminal procedure act does not have regulation as a subject, as well as the limits of materials verification of criminal case under appointment of the court session, which negatively affects the validity and timeliness of the decision about appointment of judicial proceedings, or other judicial decisions. Methods. We used general scientific research methods such as analysis, synthesis, comparison, and specific scientific methods of studies: formal legal, technical and legal. Results. The author analyzes the algorithm of actions of the judge in verification of materials of criminal case. Conclusions. The paper presents author's vision of the subject of inspection of materials received by the court of criminal cases, the production sequence of actions of a judge under appointment of the court session, the necessity of complex legal regulation in Criminal procedure code of the Russian Federation of the court's activities at the stage of processing, and the systemic, structural-logical structure and verification activities of a judge by analogy with other stages of the criminal process.
\end{abstract}

Key words: stage of court session assignment, judge's actions on verification of materials of the criminal case, powers of the judge, stage of court proceedings, criminal procedure law.

УДК 343.1

ББК 67.410 .2

\section{ПРЕДМЕТ ПРОВЕРКИ МАТЕРИАЛОВ ПОСТУПИВШЕГО В СУД УГОЛОВНОГО ДЕЛА}

Татьяна Кимовна Рябинина

Юго-Западный государственный университет, г. Курск, Российская Федерация

\begin{abstract}
Введение: в статье рассматривается проблема определения предмета проверки материалов уголовного дела, поступившего в суд для его судебного разбирательства по существу. Сложность обозначенной проблемы обусловлена отсутствием в уголовно-процессуальном законе регулирования как предмета, так и пределов проверки материалов уголовного дела в стадии назначения судебного заседания, что негативно влияет на обоснованность и своевременность принятия решения о назначении судебного разбирательства или иного судебного решения. Методы: использованы общенаучные методы исследования, такие как анализ, синтез, сравнение, а также частнонаучные методы исследования: формально-юридический, технико-юридический. Результаты: автор анализирует алгоритм действий судьи при проверке материалов уголовного дела. Выводы: в работе представлено авторское видение предмета проверки материалов поступившего в суд уголовного дела, последовательности производства действий судьи в стадии назначения судебного заседания, обоснована необходимость не фрагментарного правового регламентирования в Уголовно-процессуальном кодексе РФ деятельности суда в данной стадии процесса, а системного, структурно-логичного построения проверочной деятельности судьи по аналогии с другими стадиями уголовного процесса.

Ключевые слова: стадия назначения судебного заседания, действия судьи по проверке материалов уголовного дела, полномочия судьи, стадия судебного разбирательства, уголовно-процессуальный закон.
\end{abstract}




\section{Введение}

Задачей судьи при поступлении к нему уголовного дела является его проверка. В чем она заключается, законодатель не конкретизирует, хотя очевидно, что судья изучает письменные материалы дела, ходатайства и жалобы сторон в целях установления наличия или отсутствия оснований для назначения судебного разбирательства по делу. При этом никакой процедуры как таковой не предусмотрено, поскольку единоличные действия судьи без участия иных лиц невозможно облечь в какую-либо строгую форму, которую он обязан соблюдать. Исходя из сущности и назначения данной стадии уголовного процесса судья должен в первую очередь выявить нарушения, допущенные в стадиях возбуждения уголовного дела и предварительного расследования, в том числе ущемляющие права участников процесса, которые препятствуют рассмотрению дела в судебном разбирательстве; по возможности их устранить; обратить внимание на спорные вопросы, например, о мере пресечения, допустимости доказательств, о возможности истребовать дополнительные доказательства или изменить списки лиц, подлежащих вызову в суд, и т. п. При выявлении подобных вопросов судья не может разрешить их единолично, без участия заинтересованных лиц, то есть без судебного заседания. Для этого закон предусматривает проведение предварительного слушания, по итогам которого судья принимает соответствующее решение.

\section{Этапы прохождения уголовного дела в стадии назначения судебного заседания}

Полномочия судьи в настоящей стадии процесса зависят от этапов, через которые проходит поступившее в суд уголовное дело. Так, на первом этапе реализует свои полномочия председатель суда, решающий вопрос, какому судье передать дело для рассмотрения. Следует заметить, что этот вопрос находится в административно-организационной плоскости регламентирования, что неверно, поскольку председатель суда, передавая конкретное уголовное дело определенному судье, фактичес- ки делегирует данному судье предусмотренные уголовно-процессуальным законом полномочия по определению дальнейшей судьбы уголовного дела и, самое главное, для рассмотрения его по существу, если не будет выявлено никаких препятствий для его рассмотрения. На наш взгляд, такой порядок должен быть урегулирован законом, и более того, по аналогии с принятием уголовного дела к своему производству следователем или дознавателем (ч. 2 ст. 156 УПК РФ) председатель суда также должен выносить постановление о принятии уголовного дела к производству суда и передаче его конкретному судье.

Второй этап связан с деятельностью судьи по проверке письменных материалов поступившего в суд уголовного дела с целью установления наличия или отсутствия оснований для назначения судебного разбирательства, принятия в установленный законом срок одного из решений, предусмотренных ч. 2 ст. 227 УПК РФ. Если дело не подсудно данному суду, судья принимает решение о направлении его по подсудности, тем самым завершая на данном этапе все производство по уголовному делу в этом суде. Если судьей будут выявлены какие-либо препятствия для рассмотрения дела по существу, выражающиеся или в нарушениях закона, или в поданных ходатайствах, которые подлежат разрешению, или другие обстоятельства, требующие специальной проверки, причем обязательно в судебном заседании, с участием сторон, то судья принимает решение о назначении предварительного слушания. Таким образом, появляется третий этап - проведение предварительного слушания. И как любое судебное заседание, предварительное слушание также подготавливается - извещаются стороны, в некоторых случаях вызываются свидетели, само предварительное слушание проводится в соответствии с общими правилами проведения судебного заседания, ведется протокол судебного заседания. По результатам предварительного слушания судья выносит решение, определяющее дальнейшее движение уголовного дела, или прекращающее производство по делу, или приостанавливающее его.

Если дело подсудно данному суду и отсутствуют основания для проведения предварительного слушания, судья выносит поста- 
новление о назначении судебного заседания. Как в этом случае, так и в случае принятия аналогичного решения на предварительном слушании, с момента вынесения судьей постановления о назначении судебного заседания наступает завершающий этап производства по уголовному делу в данной стадии - подготовка к судебному разбирательству.

\section{Алгоритм действий судьи по проверке материалов уголовного дела \\ и принятию решения о дальнейшем его движении}

Анализ содержания глав 33 и 34 УПК РФ, регламентирующих порядок, сроки, последовательность действий по проверке, назначению и подготовке уголовного дела к судебному разбирательству, свидетельствует о том, что законодателем разработан определенный механизм деятельности суда в стадии назначения судебного заседания, что существенным образом отличает действующий Уголовно-процессуальный кодекс от прежних кодексов.

Среди письменных материалов уголовного дела, которые судья обязан тщательно изучить, в первую очередь следует назвать постановления о возбуждении уголовного дела и принятии дела к своему производству; о привлечении лица в качестве обвиняемого; и, несомненно, обвинительное заключение (обвинительный акт, обвинительное постановление), которое, по мнению некоторых авторов, является основанием для рассмотрения уголовного дела в стадии назначения судебного заседания, о чем свидетельствуют те вопросы, которые разрешает суд в соответствии с ч. 1 ст. 227 УПК РФ. Каждый из них может быть разрешен исключительно по результатам изучения и оценки фактических обстоятельств, приведенных в нем [6, с. 494].

В настоящее время остается востребованной теория, разработанная Н.В. Радутной, считавшей, что предусмотренная уголовно-процессуальным законом процедура расследования и судебного рассмотрения уголовных дел рассчитана на обычное уголовное дело, методика изучения многоэпизодных уголовных дел, связанная с систематизацией сведений, имеющих доказательственное значение, в отношении каждого обвиняемого по всем эпизодам, причем либо в хронологическом порядке, либо по способам совершения преступлений. Столь тщательное отношение к систематизации сведений, содержащихся в материалах дела, обусловлено тем, что вопросы, разрешаемые судом при постановлении приговора, предполагают ответы на них применительно к каждому подсудимому, а основа для получения ответов на указанные вопросы закладывается еще при изучении дела [8, с. 201-220].

В юридической литературе отдельными авторами выделялись и другие стороны предмета изучения материалов уголовного дела в стадии назначения судебного заседания, например, обстоятельства, связанные с обеспечением безопасности участников уголовного судопроизводства [1, с. 12]. А.П. Гуськова включает в предмет проверки данные о личности обвиняемого, а также обстоятельства, свидетельствующие о том, выполнено ли органами предварительного расследования требование закона о выявлении причин и условий, способствовавших совершению преступления, а также какие меры приняты органами расследования по их устранению, если в материалах дела имеется представление следователя по данному вопросу [5, с. 73-76].

В свою очередь П.А. Лупинская предлагала не ограничиваться приобщением к делу характеристик, а предоставить судам в целях реализации принципа непосредственности исследования доказательств право допрашивать лиц, подписавших характеристики, для чего в стадии назначения судебного заседания «...необходимо проверить, кто может быть допрошен в качестве свидетеля по интересующим вопросам, касающимся личности обвиняемого, и, следовательно, в случае надобности - обеспечить их вызов» [7, с. 9].

Тем самым напрашивается вывод о том, что проверке подлежат фактически все обстоятельства, имеющие значение для правильного разрешения уголовного дела, и чем тщательнее будет проведена такая проверка, тем надежнее будут выводы суда о дальнейшей судебной перспективе поступившего уголовного дела. Критики активной роли суда в процессе изучения материалов уголовного дела опасаются, что в ходе изучения материалов дела суд может вникнуть в суть предъявленного обвинения, подвергнуть сомнению пра- 
вильность правовой квалификации вмененного лицу деяния, объем предъявленного обвинения и пр., что напрямую способно повлечь создание у судьи преждевременного мнения по вопросу виновности-невиновности обвиняемого. Хотя совершенно очевидно, что значение проверки материалов дела сводится не к формированию у судьи определенного предубеждения к уголовному делу и обвиняемому, а к появлению уверенности в достаточности, добротности, полноте представленных материалов. Судья, тщательно выполняющий задачу по проверке материалов уголовного дела, выявит все огрехи, нарушения, ошибки, допущенные в досудебном производстве, и никогда не назначит судебное разбирательство по таким делам, а примет меры по устранению препятствий рассмотрения дела в следующей стадии, назначив для этого предварительное слушание. Но даже если судья не установит никаких помех и нарушений, тщательное и полное исследование материалов уголовного дела поможет ему разработать программу, план проведения судебного разбирательства в пределах, установленных законом (ч. 1 ст. 252 УПК РФ) [2, с. 80-92; 3, с. $7-$ $78 ; 9$, c. 20-68].

Между тем, как отмечалось выше, в законе не только отсутствуют нормы, регулирующие предмет и пределы проверки материалов поступившего в суд уголовного дела, сам порядок осуществления такой проверки, но и вообще нет упоминания о том, что прежде чем принять решение по поступившему уголовному делу, судья должен произвести проверку материалов этого дела. Так, буквально в ч. 1 ст. 227 УПК РФ установлено, что по поступившему уголовному делу судья принимает одно из решений: о направлении уголовного дела по подсудности, о назначении предварительного слушания, о назначении судебного заседания. Далее, в части второй той же статьи, указан срок, в течение которого принимается решение судьей, и лишь в следующей статье (ст. 228 УПК РФ) законодатель устанавливает важное правило о том, что по поступившему в суд делу судья должен выяснить в отношении каждого из обвиняемых целый комплекс вопросов, разрешение которых влияет на принятие судьей определенного решения по дальнейшему дви- жению уголовного дела, процедуре следующих действий суда, принятию некоторых организационных и обеспечительных мер и пр. Такая правовая конструкция, лишенная и логики, и даже хронологической последовательности действий суда, вносит определенный дисбаланс в правовое регулирование судебной деятельности в стадии назначения судебного заседания, препятствуя созданию необходимых условий для выполнения стоящих перед судом задач. Лишь основываясь на собственном опыте и устоявшейся судебной практике, судьи, конечно же, сумели выстроить необходимый алгоритм действий, составляющих суть их деятельности на главном этапе стадии назначения судебного заседания, длящемся от поступления уголовного дела от председателя суда до принятия одного из решений, предусмотренных ч. 1 ст. 227 УПК РФ. И хотя УПК РФ не должен уподобляться инструкции, регламентирующей подробным образом каждое действие, предпринимаемое судьей, тем не менее в законе деятельность суда в любой стадии процесса структурно-логично должна быть выстроена, как это и предусмотрено, например, в разделе, регулирующем стадию судебного разбирательства. Более того, проводя параллели с досудебным производством, следует заметить, что законодатель в ст. 144 УПК РФ, посвященной доследственной проверке сообщения о преступлении, предусмотрел процедуру осуществления такой проверки, перечислив те процессуальные действия, которые следователь и дознаватель вправе произвести на данном этапе. Трудно объяснить, почему законодатель обошел вниманием регламентацию проверочных действий суда в стадии назначения судебного заседания.

Однако необходимо подчеркнуть, что ориентиром в проверочной деятельности судьи на этапе получения уголовного дела от председателя суда можно считать круг вопросов, закрепленный в ч. 1 ст. 228 УПК РФ. Вместе с тем с учетом того, что законодателем учтены не все вопросы, подлежащие выяснению судьей, и, более того, не сведены в стройную систему, возникает необходимость определенным образом их классифицировать, что, несомненно, позволит понять и раскрыть как объем полномочий судьи, предмет и пре- 
делы проверки материалов дела, так и саму деятельность судьи по проверке уголовного дела - последовательность и полноту производимых действий и принятие соответствующих решений:

1. Проверка материалов дела с точки зрения определения возможности рассмотрения его данным судом, что включает в себя выяснение вопросов, правильно ли определена подсудность поступившего уголовного дела (этот вопрос имеется в перечне, содержащемся в ч. 1 ст. 228 УПК РФ), а также правомочен ли судья, которому передано дело для принятия одного из решений, предусмотренных ч. 1 ст. 227 УПК РФ, осуществлять такую деятельность. Только при положительных ответах на данные вопросы судья вправе приступить к непосредственной реализации своих полномочий по определению дальнейшей судьбы уголовного дела.

2. Изучение материалов уголовного дела с целью выявления нарушений закона, допущенных в досудебном производстве, причем как норм материального (уголовного) права, так и уголовно-процессуального права.

3. Проверка материалов дела с целью обнаружения нарушений прав и законных интересов участников процесса и их устранения, а также их обеспечения как в стадии назначения судебного заседания, так и в стадии судебного разбирательства.

4. Анализ доказательственной базы в имеющихся материалах уголовного дела, а также изучение поданных сторонами ходатайств, связанных с этим вопросом, с целью выявления наличия оснований для назначения предварительного слушания.

5. Изучение материалов дела с целью выявления всех обстоятельств, характеризующих личность обвиняемого, а также наличия данных о потерпевших.

6. Проверка законности избрания в стадии предварительного расследования мер пресечения в отношении обвиняемых, наличия оснований для их отмены, изменения, сохранения, продления срока содержания под стражей и срока домашнего ареста, а в необходимых случаях - избрания меры пресечения.

7. Изучение материалов дела с целью создания организационно-обеспечительных мер, направленных непосредственно на под- готовку судебного разбирательства уголовного дела, особенно, как верно отмечается отдельными авторами, когда в рамках настоящей стадии определяется форма предстоящего судебного разбирательства $[4$, с. 133].

Важно заметить при этом, что предложенное деление проверочных действий представляется условным, схематичным, поскольку очевидно, что оно в большей степени сводится не к последовательности осуществления этих действий, а к характеру обстоятельств, подлежащих выявлению, влияющих на принятие какого-либо решения судьей, то есть речь идет о предмете проверки материалов уголовного дела. Причем каждая из выделенных групп обстоятельств, которые должны быть выявлены и проверены судьей, совершенно по-разному влияет на характер принимаемых решений. Так, в одном случае судья направляет дело по подсудности, в другом назначает предварительное слушание, причем по совершенно различным основаниям, поэтому по окончании предварительного слушания, на котором судья совместно со сторонами уже в несколько иных условиях будет проверять отдельные обстоятельства, содержащиеся в материалах дела, вызвавшие определенные вопросы, могут быть приняты решения или о прекращении уголовного дела, или о возвращении его прокурору, или о назначении судебного заседания и пр.; в третьем случае судья, проверив материалы дела и не обнаружив никаких нарушений закона и препятствий к рассмотрению дела по существу, то есть установив наличие оснований для его рассмотрения в стадии судебного разбирательства, принимает решение о назначении судебного заседания без учета мнения сторон. Ряд обстоятельств, выявленных судьей при изучении уголовного дела, обусловливает принятие мер по назначению защитника, вызову дополнительных свидетелей, экспертов; по предоставлению участникам процесса времени для дополнительного ознакомления с материалами дела; по решению вопроса о мере пресечения; по обеспечению гражданского иска; по выбору определенной судебной процедуры и пр. 


\section{Выводы}

Именно тщательная проверка представленных материалов уголовного дела, осуществляемая в определенной системе познания их содержания, позволяет судье принимать решение о дальнейшем движении уголовного дела (при условии подсудности поступившего уголовного дела данному суду), в первую очередь через призму вопроса: есть ли основания для назначения судебного разбирательства или предварительного слушания? Важность решения данного вопроса обусловлена тем, что порой судьи уже непосредственно при рассмотрении дела по существу обнаруживают нарушения, пробелы, препятствия для разрешения дела, влекущие принятие решения или о возвращении дела прокурору, или о приостановлении, или об отложении производства по делу, что не только осложняет разбирательство дела по существу и влечет нарушение разумного срока рассмотрения дела, но и наносит ощутимый вред авторитету судебной власти.

Таким образом, подытоживая, следует отметить, что в предмет проверки судом в стадии назначения судебного заседания включаются все обстоятельства, связанные с установлением оснований для назначения судебного заседания, то есть обстоятельства, входящие в предмет доказывания по уголовному делу (ст. 73 УПК РФ), и обстоятельства, связанные с разрешением вопросов, подлежащих обязательному выяснению при изучении уголовного дела (ч. 1 ст. 228 УПК РФ), а также обстоятельства, связанные с подготовкой судебного разбирательства и принятием организационнообеспечительных мер для его проведения.

\section{СПИСОК ЛИТЕРАТУРЫ}

1. Авдеев, М. А. Правовые и организационные основы обеспечения безопасности участников уголовного судопроизводства / М. А. Авдеев.Воронеж : Истоки, 2007. - 143 с.

2. Бозров, В. М. Современные проблемы российского правосудия по уголовным делам в деятельности военных судов (вопросы теории и практики) / В. М. Бозров. - Екатеринбург : Урал. гос. юрид. академия, 1999. - $231 \mathrm{c.}$

3. Бушуев, Г. И. Судья в уголовном процессе / Г. И. Бушуев. - М. : Юридическая литература, 1984. $-112 \mathrm{c}$.
4. Волколуп, О. В. Система уголовного судопроизводства и проблемы ее совершенствования / О. В. Волколуп. - СПб. : Юридический центр Пресс, 2003. $-267 \mathrm{c}$.

5. Гуськова, А. П. Выявление судом обстоятельств, характеризующих личность обвиняемого / А. П. Гуськова // Избранные труды / А. П. Гуськова. - Оренбург : Изд. центр ОГАУ, 2007. - С. 45-101.

6. Комментарий к Уголовно-процессуальному кодексу Российской Федерации / отв. ред. Д. Н. Козак, Е. Б. Мизулина. - 2-е изд., перераб. и доп. - М. : Юристь, 2004. - 823 с.

7. Лупинская, П. А. Установление обстоятельств, характеризующих личность обвиняемого / П. А. Лупинская // Советская юстиция. - 1982. - № 2. - С. 9-10.

8. Радутная, Н. В. Подготовка и судебное разбирательство многоэпизодных групповых дел / Н. В. Радутная // Избранное / Н. В. Радутная. - М. : РАП, 2010. - С. 198-233.

9. Халдеев, Л. С. Судья в уголовном процессе / Л. С. Халдеев. - М. : Юрайт, 2000. - 501 с.

\section{REFERENCES}

1. Avdeev M.A. Pravovye i organizatsionnye osnovy obespecheniya bezopasnosti uchastnikov ugolovnogo sudoproizvodstva [The legal and organizational framework for security in criminal proceedings]. Voronezh, Istoki Publ., 2007. 143 p.

2. Bozrov V.M. Sovremennye problemy rossiyskogo pravosudiya po ugolovnym delam $v$ deyatelnosti voennykh sudov (voprosy teorii $i$ praktiki) [Modern problems of Russian justice in criminal cases in military courts (Theory and Practice)]. Ekaterinburg, Ural. gos. yurid. akademiya, 1999. 231 p.

3. Bushuev G.I. Sudya v ugolovnom protsesse [The judge in the criminal process]. Moscow, Yuridicheskaya literature Publ., 1984. 112 p.

4. Volkolup O.V. Sistema ugolovnogo sudoproizvodstva i problemy ee sovershenstvovaniya [The criminal justice system and problems of its improvement]. Saint Petersburg, Yuridicheskiy tsentr Press, 2003. 267 p.

5. Guskova A.P. Vyyavlenie sudom obstoyatelstv, kharakterizuyushchikh lichnost obvinyaemogo [Identification of the court the circumstances that characterize the personality of the accused]. Izbrannye trudy [Selected works]. Orenburg, Izd. tsentr OGAU, 2007, pp. 45-101.

6. Kozak D.N., Mizulina E.B. Kommentariy $k$ Ugolovno-protsessualnomu kodeksu Rossiyskoy Federatsii [Comment to the Criminal Procedure Code of the Russian Federation]. Moscow, Yurist Publ., 2004. 823 p.

7. Lupinskaya P.A. Ustanovlenie obstoyatelstv, kharakterizuyushchikh lichnost obvinyaemogo [The establishment of circumstances that characterize the 


\section{ПРОЦЕССУАЛЬНОЕ ПРАВО: ВОПРОСЫ ТЕОРИИ И ПРАВОПРИМЕНЕНИЯ}

personality of the accused]. Sovetskaya yustitsiya, 1982, no. 2, pp. 9-10.

8. Radutnaya N.V. Podgotovka i sudebnoe razbiratelstvo mnogoepizodnykh gruppovykh del [Preparation and trial of multi-episode group cases].
Izbrannoe [Selected works]. Moscow, RAP Publ., 2010, pp. 198-233.

9. Khaldeev L.S. Sudya v ugolovnom protsesse [The judge in the criminal process]. Moscow, Yurayt Publ., 2000. 501 p.

\section{Information About the Author}

Tatyana K. Ryabinina, Candidate of Juridical Sciences, Professor, Head of Department of Criminal Process and Criminalistics, Southwest State University, Honoured Lawyer of the Russian Federation, 50 let Oktyabrya St., 94, 305040, Kursk, Russian Federation, tatyanakimovna-r@yandex.ru.

\section{Информация об авторе}

Татьяна Кимовна Рябинина, кандидат юридических наук, профессор, заведующая кафедрой уголовного процесса и криминалистики, Юго-Западный государственный университет, заслуженный юрист РФ, ул. 50 лет Октября, 94, 305040 г. Курск, Российская Федерация, tatyanakimovna-r@yandex.ru. 